\title{
Ambient-pressure molecular superconductor with a superlattice containing layers of tris(oxalato)rhodate enantiomers and 18-crown- 6
}

\author{
Lee Martin, ${ }^{\dagger *}$ Alexander L. Morritt, ${ }^{\dagger}$ Jordan R. Lopez, ${ }^{\dagger}$ Hiroki Akutsu, ${ }^{\ddagger}$ Yasuhiro Nakazawa,${ }^{\ddagger}$ Shusaku \\ Imajo $^{\ddagger}$ and Yoshihiko Ihara $^{\S}$
}
${ }^{\dagger}$ School of Science and Technology, Nottingham Trent University, Clifton Lane, Nottingham, NG11 8NS, UK. ${ }^{\ddagger}$ Department of Chemistry, Graduate School of Science, Osaka University, 1-1 Machikaneyama-cho, Toyonaka, Osaka 560- 0043, Japan.

§Department of Quantum and Condensed Matter Physics, School of Science, Hokkaido University, Kita-ku, Sapporo, 0600810, Hokkaido, Japan.

\begin{abstract}
We report a novel multilayered organic-inorganic hybrid material, $\beta$ "-(BEDT-TTF $)_{2}\left[\left(\mathrm{H}_{2} \mathrm{O}\right)\left(\mathrm{NH}_{4}\right)_{2} \mathrm{Rh}\left(\mathrm{C}_{2} \mathrm{O}_{4}\right)_{3}\right] .18$ crown-6. This is the first molecular superconductor to have a superlattice with layers of both BEDT-TTF and 18-crown-6, and also the first with the anion tris(oxalato)rhodate. This is the 2D superconductor with the widest gap between conducting layers where only a single donor packing motif is observed ( $\beta$ "). The strong 2D nature of this system strongly suggests that the superconducting transition is a KT transition. A superconducting Tc of $2.7 \mathrm{~K}$ at ambient pressure was found by transport and $2.5 \mathrm{~K}$ by magnetic susceptibility measurements.
\end{abstract}

The discovery of superconductivity in $\beta$ "-(BEDTTTF $)_{4}\left[\left(\mathrm{H}_{3} \mathrm{O}\right) \mathrm{Fe}\left(\mathrm{C}_{2} \mathrm{O}_{4}\right)_{3}\right]$. benzonitrile ${ }^{1}$ triggered an enormous amounts of research owing to the combination of magnetism and conductivity in the same crystal lattice. Over 20 years a large family of isostructural salts have been prepared by changing the guest solvent molecule or the metal centre ( $\mathrm{Fe}, \mathrm{Cr}$, $\mathrm{Ga}, \mathrm{Ru}$ ) and the electrical and magnetic properties of this family of superconductors have been extensively studied. ${ }^{2}$

This family has also produced a variety of different structural phases including antiferromagnetic semiconductors, ${ }^{3}$ ferromagnetic metals, ${ }^{4}$ and a proton-conducting metal ${ }^{5}$ through small changes in the formula. However, despite extensive research on this family of tris(oxalato)metallate salts, only the one superconducting phase is known. We report here a new ambient-pressure superconductor which has the novel superlattice $\quad \beta$ "-(BEDT-TTF $)_{2}\left[\left(\mathrm{H}_{2} \mathrm{O}\right)\left(\mathrm{NH}_{4}\right)_{2} \mathrm{Rh}\left(\mathrm{C}_{2} \mathrm{O}_{4}\right)_{3}\right] .18$ crown-6.

Previous efforts to produce a chiral superconductor from tris(oxalato)metallate were unsuccessful owing to the racemisation of $\mathrm{Cr}$ (oxalate) $)_{3}$ during the period of crystal growth. ${ }^{6} \mathrm{Rh}$ (oxalate) 3 racemises slower and could be a more suitable candidate. There has been extensive effort in the past 15 years to observe multifunctionality through combination of chirality with conductivity in the same lattice. Molecular conductors have been synthesized from chiral donor molecules ${ }^{7}$ and chiral anions, ${ }^{8}$ and the electrical magneto-chiral anisotropy effect $^{9}$ has recently been observed in enantiopure $(R, R)$ - or $(S, S)$ - (DM-EDT-TTF) ${ }_{2} \mathrm{ClO}_{4} .^{10}$

We report here the synthesis, crystal structure, electrical and magnetic properties for $\beta$ "-(BEDTTTF $)_{2}\left[\left(\mathrm{H}_{2} \mathrm{O}\right)\left(\mathrm{NH}_{4}\right)_{2} \mathrm{Rh}\left(\mathrm{C}_{2} \mathrm{O}_{4}\right)_{3}\right]$.18-crown-6. This salt has a guest molecule of 18 -crown- 6 protruding into the hexagonal cavity which provides the first example in this family which has a superlattice and also shows ambient pressure superconductivity.

$\beta$ ”-(BEDT-TTF $)_{2}\left[\left(\mathrm{H}_{2} \mathrm{O}\right)\left(\mathrm{NH}_{4}\right)_{2} \mathrm{Rh}\left(\mathrm{C}_{2} \mathrm{O}_{4}\right)_{3}\right]$.18-crown-6 (I) crystallises in the triclinic space group $P-1$, with two crystallographically independent BEDT-TTF molecules, two $\mathrm{NH}_{4}{ }^{+}$, one $\mathrm{H}_{2} \mathrm{O}$, one $\mathrm{Rh}\left(\mathrm{C}_{2} \mathrm{O}_{4}\right)_{3}{ }^{3-}$, and one 18-crown- 6 molecule. The crystal structure is built up of successive layers of $\beta$ "BEDT-TTF (layer A), $\Lambda$ - $\left(\mathrm{NH}_{4}\right) \mathrm{Rh}\left(\mathrm{C}_{2} \mathrm{O}_{4}\right)_{3} \quad$ (layer B), $\left(\mathrm{H}_{2} \mathrm{O}\right)\left(\mathrm{NH}_{4}\right) 18$-crown-6 (layer $\mathrm{C}$ ), and $\Delta$ - $\left(\mathrm{NH}_{4}\right) \mathrm{Rh}\left(\mathrm{C}_{2} \mathrm{O}_{4}\right)_{3}$ (layer D) giving an ABCDABCDA... pattern (Fig. 1).

The anion layer in $\mathbf{I}$ (Fig. 2) contains $\mathrm{Rh}\left(\mathrm{C}_{2} \mathrm{O}_{4}\right)_{3}{ }^{3-}$ and $\mathrm{NH}_{4}{ }^{+}$ adopting the familiar hexagonal packing found in the paramagnetic superconducting series $\beta$ "-(BEDT$\mathrm{TTF})_{4}\left[(\mathrm{~A}) \mathrm{M}\left(\mathrm{C}_{2} \mathrm{O}_{4}\right)_{3}\right]$.Guest ${ }^{1,11}$ series. Each anion layer contains a single $\mathrm{Rh}\left(\mathrm{C}_{2} \mathrm{O}_{4}\right)_{3} 3^{3-}$ enantiomer with the adjacent layer containing only the opposite enantiomer.

In salt $\mathbf{I}$ in contrast to previous $\beta$ " salts there is a layer of 18 crown- 6 molecules sandwiched between the two anion layers. Each crown ether molecule protrudes into the hexagonal cavity of only one anion layer (Fig. 1). This has been observed previously in a proton-conducting metallic salt. ${ }^{5}$ 


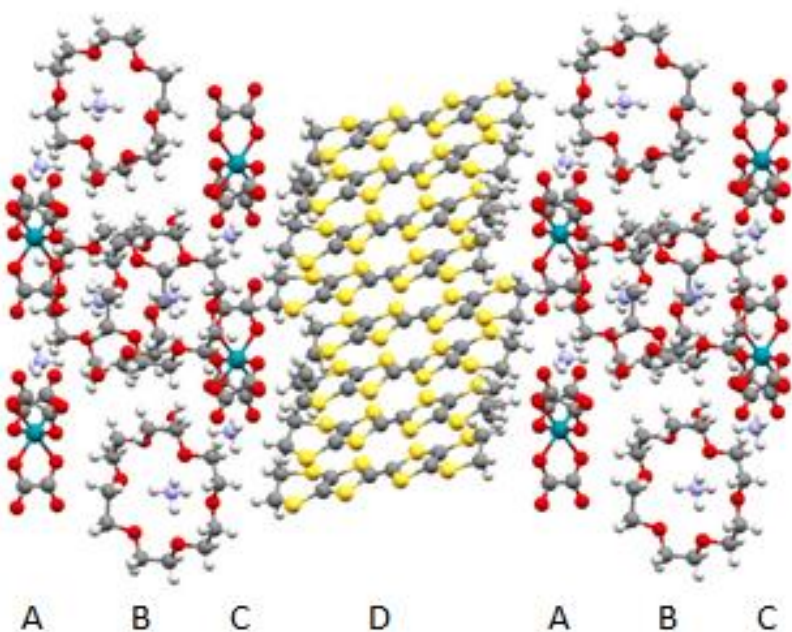

Fig. 1 Crystal structure of $\mathbf{I}$ showing the alternating ABCDABCDA.... layered superlattice.

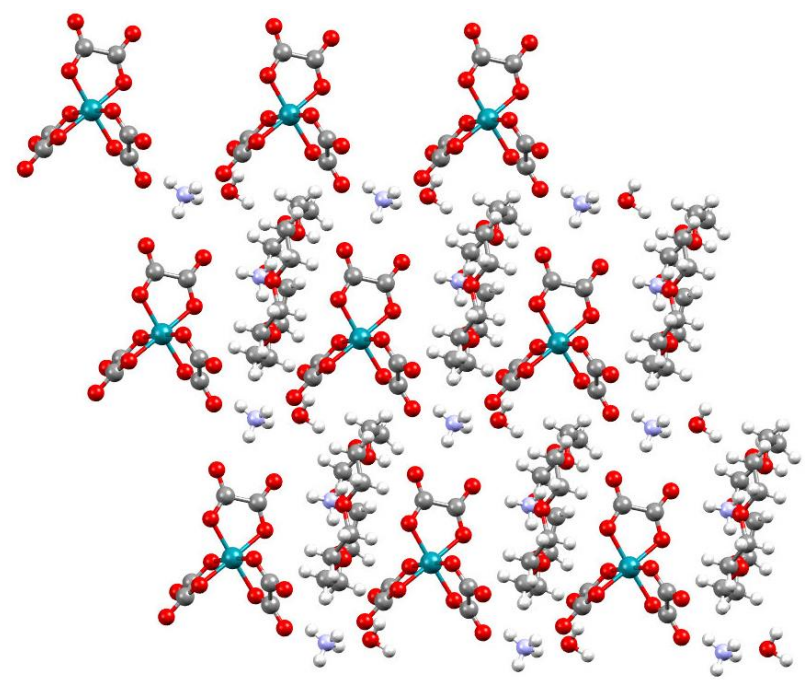

Fig. 2 Anion layer of I showing the neighbouring crown ether molecules sited at the hexagonal cavities.

The hexagonal cavity in $\mathbf{I}$ is larger that those in the $\beta$ "-(BEDT$\mathrm{TTF})_{2}\left[\left(\mathrm{H}_{3} \mathrm{O}\right) \mathrm{Fe}\left(\mathrm{C}_{2} \mathrm{O}_{4}\right)_{3}\right]$.halobenzene series. At $110 \mathrm{~K}$ the dimensions of the hexagonal cavity has hexagon sides of $6.37(1), 6.45(1)$, and 6.34(1) $\AA$ and a side-to-side width of $11.25(1) \AA$. This is in contrast to the $\beta$ "-(BEDT$\mathrm{TTF})_{2}\left[\left(\mathrm{H}_{3} \mathrm{O}\right) \mathrm{Fe}\left(\mathrm{C}_{2} \mathrm{O}_{4}\right)_{3}\right]$.halobenzene series which has hexagon sides 6.33(1), 6.16(1), and 6.33(1) $\AA$ and a width 10.26(1) $\AA_{\text {at }}$ $120 \mathrm{~K}^{11}$

The size, shape and orientation of the guest molecule sitting in the hexagonal cavity is known to influence the order/disorder of the terminal ethylene groups on nearby BEDT-TTF molecules and thus affect the transport properties or destabilise the superconducting transition.

The asymmetric unit of $\mathbf{I}$ contains two crystallographically independent BEDT-TTF molecules which pack in a $\beta$ "-packing motif (Fig. 3). One donor has a sofa conformation at one end and a half-chair at the other end, whilst the other donor molecule has a sofa at one end and a boat conformation at the other. There are a number of short S...S contacts below the sum of the van der Waals radii $(<3.6 \AA$ ) which are all side-to side between BEDT-TTF molecules: S20..S35 3.571(1), $\mathrm{S} 25 \ldots \mathrm{S} 38(1) \quad 3.566(1), \quad \mathrm{S} 25 \ldots \mathrm{S} 43(1) \quad 3.527(1), \mathrm{S} 30 \ldots \mathrm{S} 50$ $3.327(1), \quad \mathrm{S} 32 \ldots \mathrm{S} 50 \quad 3.278(1), \quad \mathrm{S} 46 \ldots \mathrm{S} 53 \quad 3.353(1)$, and S46...S55 3.487(1) A.

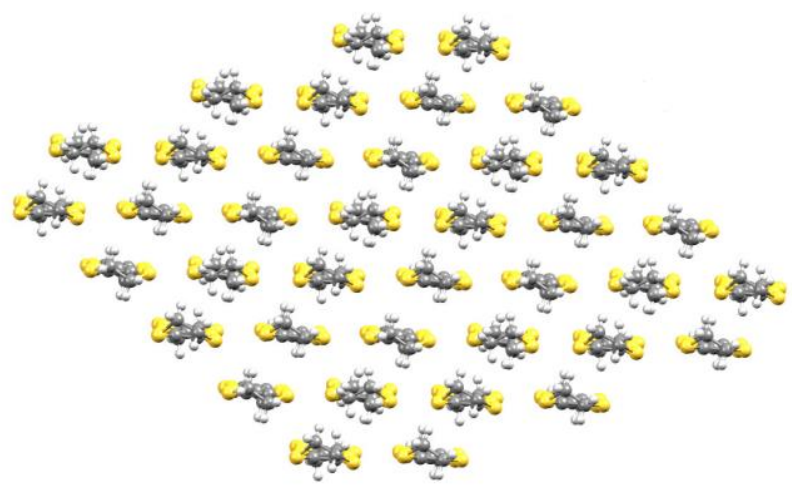

Fig. 3 BEDT-TTF layer of I viewed along the molecular long axis.

From the donor $\mathrm{C}=\mathrm{C}$ and $\mathrm{C}-\mathrm{S}$ bond lengths ${ }^{12}$ (Table 1 ) it can be approximated that the BEDT-TTF molecules all have a charge close to $0.5^{+}+/-0.1$ as expected for the formula $\beta$ "$(\mathrm{BEDT}-\mathrm{TTF})_{2}\left[\left(\mathrm{H}_{2} \mathrm{O}\right)\left(\mathrm{NH}_{4}\right)_{2} \mathrm{Rh}\left(\mathrm{C}_{2} \mathrm{O}_{4}\right)_{3}\right]$. 18-crown-6.

Table 1 Average bond lengths in BEDT-TTF molecules of $\mathbf{I}$ and approximation of charge on the molecules. $\delta=(\mathrm{b}+\mathrm{c})-(\mathrm{a}+\mathrm{d}), Q$ $=6.347-7.463 \delta .{ }^{12}$

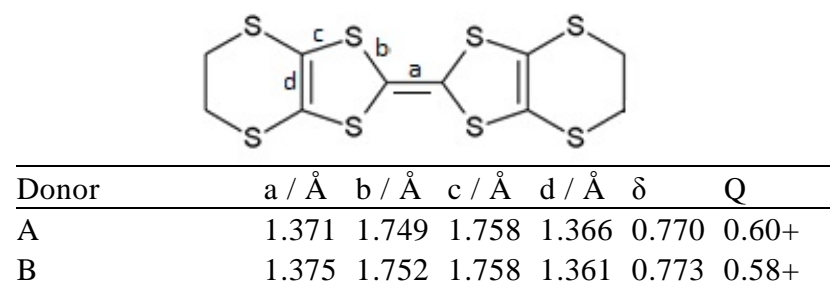

Electrical resistivity measurements performed on I using the four probe method shows low room temperature resistivity which decreases upon cooling as expected for a metal. A sharp decrease is observed below $2.7 \mathrm{~K}$ indicative of a superconducting transition (Fig. 4). Unlike other superconductors in the $\beta$ " family there is no shoulder observed a few Kelvin above the superconducting transition. ${ }^{11}$ The superconducting nature of the transition is confirmed by the application of magnetic field which suppresses the transition (Fig. 5).

Variable temperature susceptibility measurements were performed on a polycrystalline sample at 20 Oe down to $1.8 \mathrm{~K}$ and a superconducting transition was observed at $2.5 \mathrm{~K}$ (Fig. 6 , top). The transition could be suppressed by the application of fields $>1 \mathrm{kOe}$ (Fig. 6, bottom). 


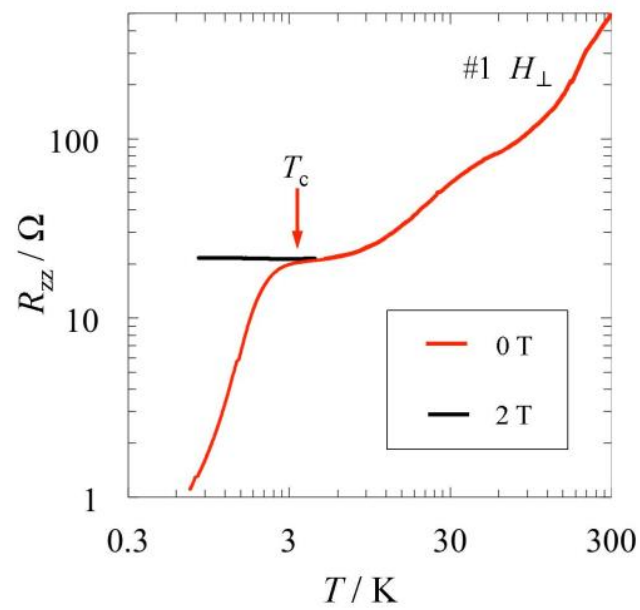

Fig. 4 Resistivity data for $\mathbf{I}$ from room temperature to $0.8 \mathrm{~K}$
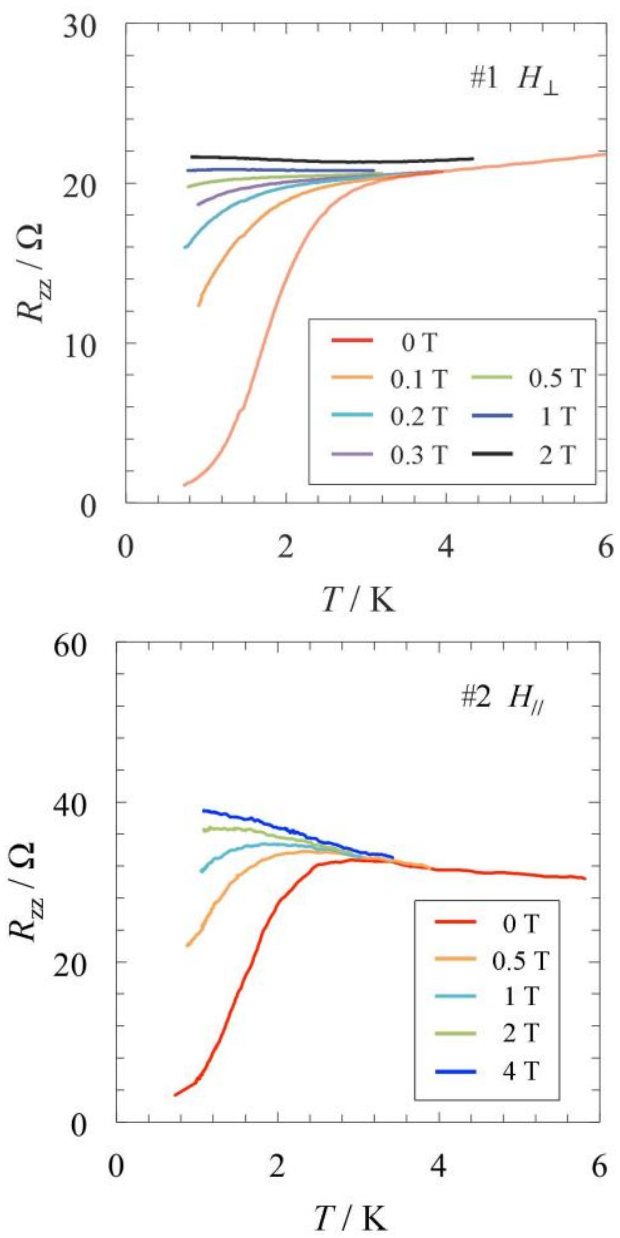

Fig. 5 Resistivity of I under different applied magnetic fields applied perpendicular or parallel to the conduction plane.
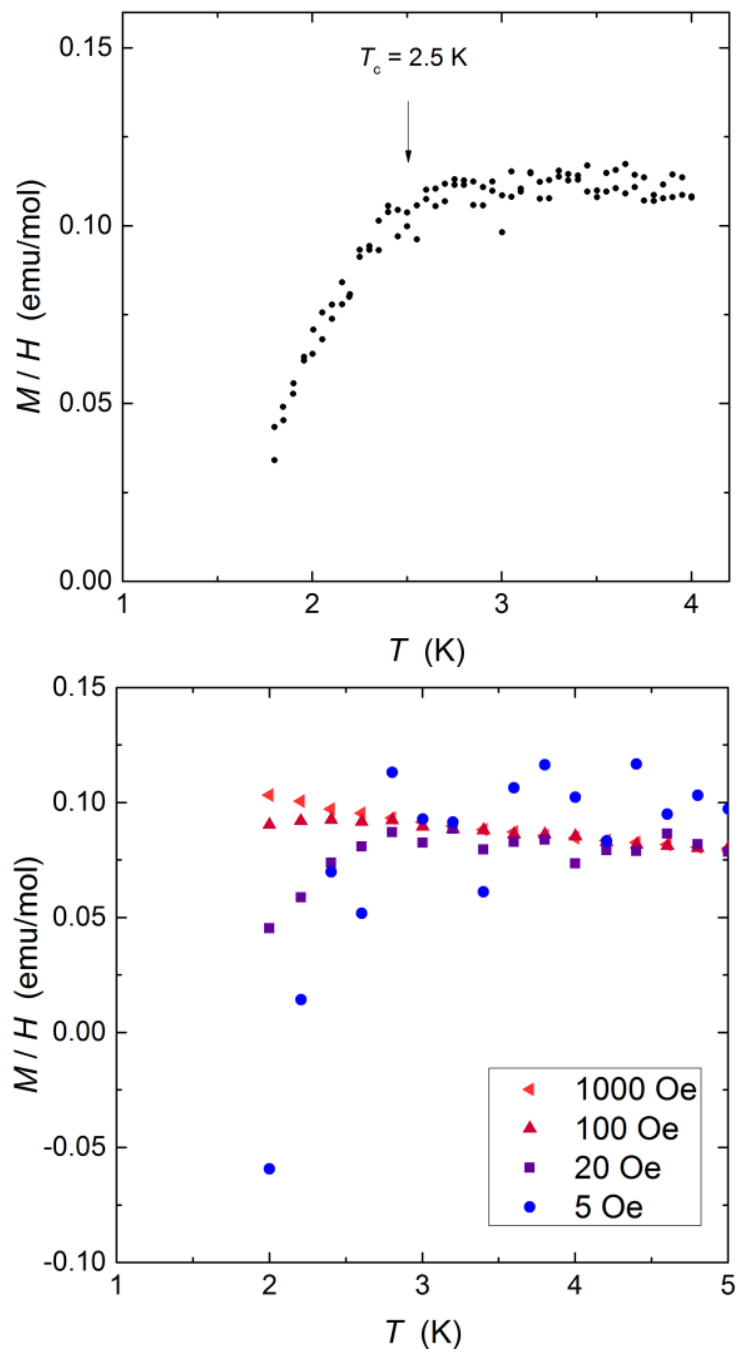

Fig. 6 Magnetic susceptibility for I at 20G showing onset of superconductivity at $2.5 \mathrm{~K}$ (top); magnetic susceptibility for I at fields up to $1000 \mathrm{Oe}$ (bottom). 
In conclusion, the superconductor $\quad \beta$ "-(BEDTTTF $)_{2}\left[\left(\mathrm{H}_{2} \mathrm{O}\right)\left(\mathrm{NH}_{4}\right)_{2} \mathrm{Rh}\left(\mathrm{C}_{2} \mathrm{O}_{4}\right)_{3}\right] .18$-crown-6 is the first to contain tris(oxalato)rhodate and has a novel multilayered packing arrangement of BEDT-TTF, $\mathrm{Rh}\left(\mathrm{C}_{2} \mathrm{O}_{4}\right)_{3}$, and 18-crown6 . This is the $2 \mathrm{D}$ superconductor with the widest gap between conducting layers where only a single donor packing motif is observed ( $\beta$ "). The strong 2D nature of this system strongly suggests that the superconducting transition is a KT transition. We are now investigating the synthesis of a variety of para-, ferro- or anti- ferromagnetic derivatives which could also be synthesized by replacing the rhodium to allow a systematic study of the effect upon the conductivity.

\section{Notes and references}

$\dagger$ Experimental Details: $200 \mathrm{mg}$ ammonium tris(oxalato)rhodate and $400 \mathrm{mg}$ 18-crown-6 ether dissolved in $10 \mathrm{mls}$ fluorobenzene: $10 \mathrm{mls} \quad$ chlorobenzene: $20 \mathrm{mls} \quad 1,2,4-$ trichlorobenzene: $4 \mathrm{mls}$ ethanol were placed in a two-compartment $\mathrm{H}$-shaped electrochemical cell containing $20 \mathrm{mg}$ ET in the anode compartment. A large quantity of black needle crystals were obtained upon applying a current of $1.0 \mu \mathrm{A}$ across the cell for three weeks in a dark box on a vibration-free bench.

† Crystal data: $\mathbf{I}: \mathrm{C}_{38} \mathrm{H}_{50} \mathrm{~N}_{2} \mathrm{Rh}_{1} \mathrm{O}_{19} \mathrm{~S}_{16}, M=1454.68$, black needle, $a=10.2970(5), b=11.2532(4), c=27.4339(11) \AA, \alpha=86.383(3)$, $\beta=82.411(4), \gamma=64.325(4)^{\circ}, U=2839.9(2) \AA^{3}, T=110 \mathrm{~K}$, space group $P-1, \mathrm{Z}=2, \mu=0.960 \mathrm{~mm}^{-1}$, reflections collected $=27169$, independent reflections $=12671, R 1=0.0471, w R 2=0.1175\left[F^{2}>\right.$ $\left.2 \sigma\left(F^{2}\right)\right], R 1=0.0531, w R 2=0.1209$ (all data).

$\S$ CCDC 1498941 contains supplementary X-ray crystallographic data for I. This data can be obtained free of charge via http://www.ccdc.cam.ac.uk/conts/retrieving.html, or from the Cambridge Crystallographic Data Centre, Union Road, Cambridge, CB2 1EZ; $\operatorname{fax}(+44)$ 1223-336-033 or email: deposit@ccdc.cam.ac.uk.

LM thanks the Royal Society of Chemistry for a Journals Grant for International Authors. This work has been supported by the Royal Society [Research Grants (RG100853 and RG081209), International Exchange Scheme (IE130367), and International Joint Project (JP0869972)].

1 M. Kurmoo, A. W. Graham, P. Day, S. J. Coles, M. B. Hursthouse, J. L. Caulfield, J. Singleton, F. L. Pratt, W. Hayes, L. Ducasse and P. Guionneau, Superconducting and Semiconducting Magnetic Charge Transfer Salts: (BEDT$\mathrm{TTF})_{4} \mathrm{AFe}\left(\mathrm{C}_{2} \mathrm{O}_{4}\right)_{3} . \mathrm{C}_{6} \mathrm{H}_{5} \mathrm{CN}\left(\mathrm{A}=\mathrm{H}_{2} \mathrm{O}, \mathrm{K}, \mathrm{NH}_{4}\right), J$. Am. Chem. Soc., 1995, $117,12209$.

2 E. Coronado and P. Day, Magnetic Molecular Conductors, Chem. Rev., 2004, 104, 5419-5448.

3 B. Zhang, Y. Zhang and D. Zhu, (BEDTTTF $)_{3} \mathrm{Cu}_{2}\left(\mathrm{C}_{2} \mathrm{O}_{4}\right)_{3}\left(\mathrm{CH}_{3} \mathrm{OH}\right)_{2}$ : an organic-inorganic hybrid antiferromagnetic semiconductor, Chem. Commun., 2012, 48, 198-199.

4 E. Coronado, J. R. Galán-Mascarós, C. J. Gómez-García and V. Laukhin, Coexistence of ferromagnetism and metallic conductivity in a molecule-based layered compound, Nature, 2000, 408, 447.
5 A. Akutsu-Sato, H. Akutsu, S. S. Turner, P. Day, M. R. Probert, J. A. K. Howard, T. Akutagawa, S. Takeda, T. Nakamura and T. Mori, The First Proton-Conducting Metallic Ion-Radical Salts, Angew.Chem.Ind.Ed., 2005, 44, 291.

6 L. Martin, S. S. Turner, P. Day, K. M. A. Malik, S. J. Coles and M. B. Hursthouse, Polymorphism based on molecular stereoisomerism in tris(oxalato) $\mathrm{Cr}$ (III) salts of bedt-ttf, Chem. Commun., 1999, 513.

7 J. R. Galán-Mascarós, E. Coronado, P. A. Goddard, J. Singleton, A. I. Coldea, J. D. Wallis, S. J. Coles and A. Alberola, A Chiral Ferromagnetic Molecular Metal, J. Am. Chem. Soc., 2010, 132, 9271; F. Pop, P. Auban-Senzier, A. Frąckowiak, K. Ptaszyński, I. Olejniczak, J. D. Wallis, E. Canadell and N. Avarvari, Chirality Driven Metallic versus Semiconducting Behavior in a Complete Series of Radical Cation Salts Based on Dimethyl-EthylenedithioTetrathiafulvalene (DM-EDT-TTF), J. Am. Chem. Soc., 2013, 135, 17176.

8 M. Atzori, F. Pop, P. Auban-Senzier, C. J. Gómez-García, E. Canadell, F. Artizzu, A. Serpe, P. Deplano, N. Avarvari and M. L. Mercuri, Structural Diversity and Physical Properties of Paramagnetic Molecular Conductors Based on Bis(ethylenedithio)tetrathiafulvalene (BEDT-TTF) and the Tris(chloranilato)ferrate(III) Complex, Inorg. Chem., 2014, 53(13), 7028; M. Atzori, F. Pop, P. Auban-Senzier, E. Canadell, R. Clérac, M. L. Mercuri and N. Avarvari, "Complete Series of Chiral Paramagnetic Molecular Conductors Based on Tetramethyl-bis(ethylenedithio)-tetrathiafulvalene (TMBEDT-TTF) and Chloranilate-Bridged Heterobimetallic Honeycomb Layers", Inorg. Chem., 2015, 54(7), 3643-3653.

9 G. L. J. A. Rikken and E. Raupach, Observation of magneto-chiral dichroism, Nature, 1997, 390, 493; V. Krstic, S. Roth, M. Burghard, K. Kern and G. L. J. A. Rikken, Magneto-chiral anisotropy in charge transport through single-walled carbon nanotubes, J. Chem. Phys., 2002, 117, 11315; G. L. J. A. Rikken, A new twist on spintronics, Science, 2011, 331, 864.

10 F. Pop, P. Auban-Senzier, E. Canadell, G. L. J. A. Rikken, N. Avarvari, Electrical magnetochiral anisotropy in a bulk chiral molecular conductor, Nature Commun., 2014, 5, 3757.

11 E. Coronado, S. Curreli, C. Giménez-Saiz and C. J. GómezGarcía, The Series of Molecular Conductors and Superconductors $\mathrm{ET}_{4}\left[\mathrm{AFe}\left(\mathrm{C}_{2} \mathrm{O}_{4}\right)_{3}\right] \cdot \mathrm{PhX} \quad(\mathrm{ET}=$ bis(ethylenedithio)tetrathiafulvalene; $(\mathrm{C} 2 \mathrm{O} 4) 2-=$ oxalate; $\mathrm{A}^{+}=$ $\mathrm{H}_{3} \mathrm{O}^{+}, \mathrm{K}^{+} ; \mathrm{X}=\mathrm{F}, \mathrm{Cl}, \mathrm{Br}$, and I): Influence of the Halobenzene Guest Molecules on the Crystal Structure and Superconducting Properties, Inorg. Chem., 2012, 51, 1111.

12 P. Guionneau, C. J. Kepert, D. Chasseau, M. R. Truter and P. Day, Determining the charge distribution in BEDT-TTF salts, Synth. Met., 1997, 86, 1973.

\section{AUTHOR INFORMATION}

\section{Corresponding Author}

Email: lee.martin@ntu.ac.uk

\section{Notes}

The authors declare no competing financial interests. 

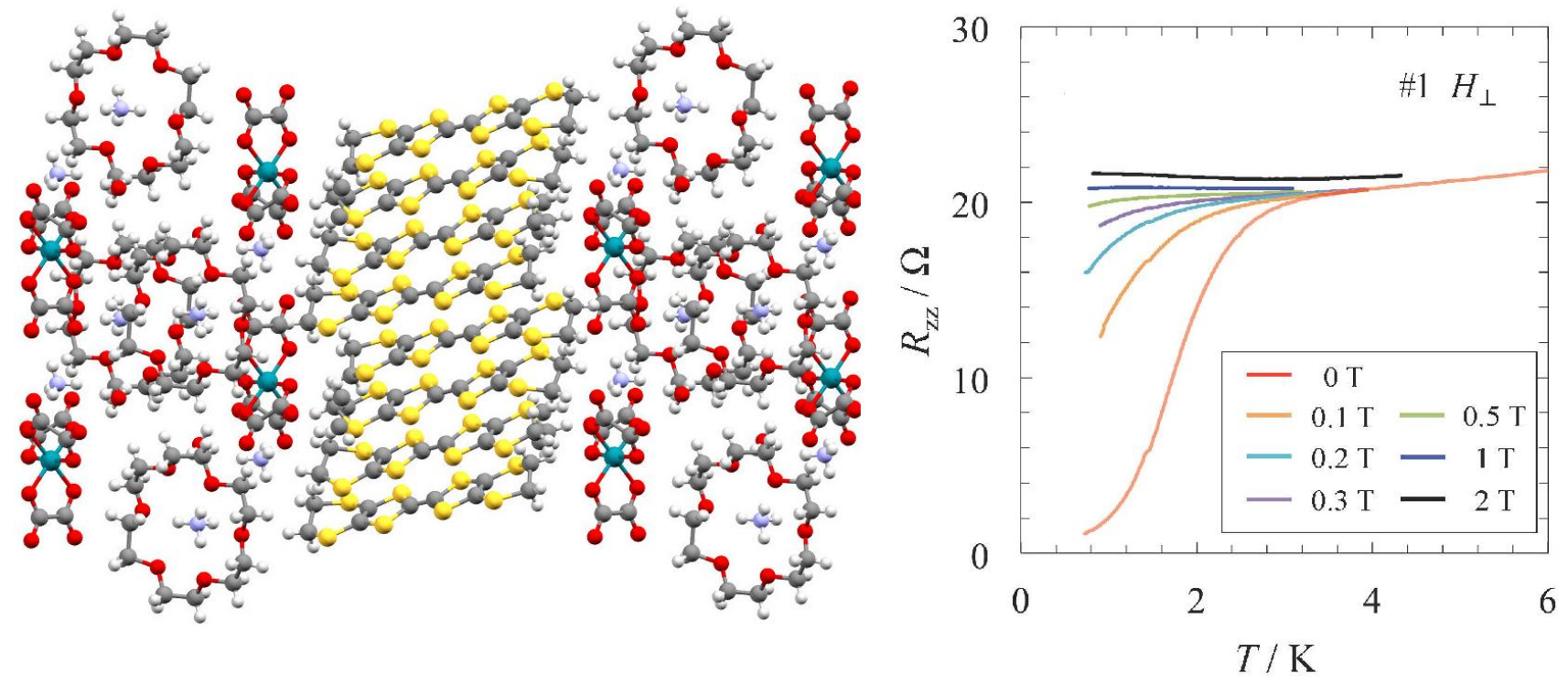

We report a novel multilayered organic-inorganic hybrid material, $\beta$ "'-(BEDT$\mathrm{TTF})_{2}\left[\left(\mathrm{H}_{2} \mathrm{O}\right)\left(\mathrm{NH}_{4}\right)_{2} \mathrm{Rh}\left(\mathrm{C}_{2} \mathrm{O}_{4}\right)_{3}\right] .18$-crown-6. This is the first molecular superconductor to have a superlattice with layers of both BEDT-TTF and 18-crown-6, and also the first with the anion tris(oxalato)rhodate. This is the 2D superconductor with the widest gap between conducting layers where only a single donor packing motif is observed ( $\beta$ "). The strong $2 \mathrm{D}$ nature of this system strongly suggests that the superconducting transition is a KT transition. A superconducting Tc of $2.7 \mathrm{~K}$ at ambient pressure was found by transport and $2.5 \mathrm{~K}$ by magnetic susceptibility measurements. 